
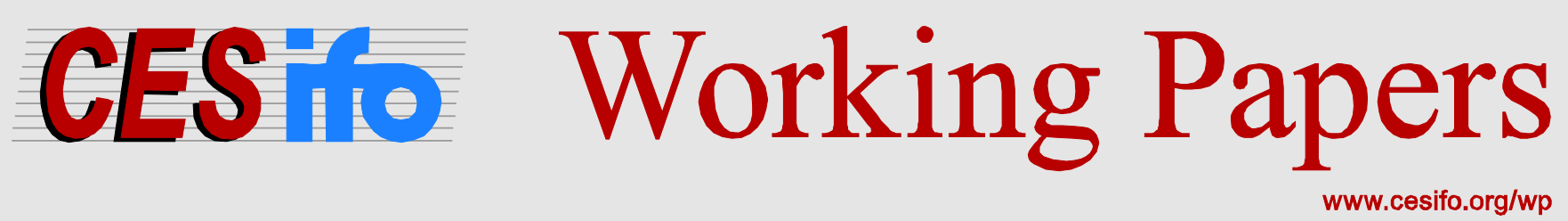

\title{
Does Capital Tax Uncertainty Delay Irreversible Risky Investment?
}

\author{
Rainer Niemann \\ Caren Sureth-Sloane
}

CESIFO WORKING PAPER NO. 6046

CATEgORY 1: PUBlic FinANCE

August 2016

An electronic version of the paper may be downloaded

- from the SSRN website:

- from the RePEc website:

- from the CESifo website:

WwW.SSRN.com

Www.RePEc.org

www.CESifo-group.org/wp 


\title{
Does Capital Tax Uncertainty Delay Irreversible Risky Investment?
}

\begin{abstract}
Tax uncertainty is often claimed to be harmful for investments. Capital taxes, such as property and wealth taxes, are particularly exposed to tax uncertainty. Capital tax uncertainty emerges from expected tax reforms, the unclear outcome of future tax audits, and simplified estimates of capital tax bases in investment models. Uncertain returns on investment as well as stochastic taxation contribute to overall uncertainty and may significantly affect investment decisions. Hitherto, it is unknown how capital tax uncertainty affects investment timing. However, it is well known that both uncertainty and capital tax may be harmful for investment and decelerate investment activities. We are the first to study the investment timing effects of stochastic capital taxes in a real options setting with risky investment opportunities. Our results indicate that even risk neutral investors are sensitive with respect to capital tax risk and may react in a surprising manner to a newly introduced stochastic capital tax. As an apparently paradoxical investment effect, we find that increased capital tax uncertainty can accelerate risky investment if such uncertainty is sufficiently low compared to cash flow uncertainty. In contrast, high capital tax risk delays high-risk innovative investment projects. To reduce unintended consequences of uncertain tax policy, tax legislators and tax authorities should avoid high levels of capital tax uncertainty. Broadening the capital tax base or increasing the capital tax rate induces ambiguous timing effects. Furthermore, high-growth investments are likely to be postponed if they experience a capital tax cut. Since investment reactions upon tax reforms are well-known to affect income and wealth distribution, reliable estimations of the impact of taxes on economic decisions are necessary.
\end{abstract}

JEL-Codes: H210, H250.

Keywords: property tax, capital tax, investment decisions, real options, timing, flexibility, uncertainty.

\author{
Rainer Niemann \\ Karl-Franzens University \\ Graz / Austria \\ niemann@uni-graz.at
}

\author{
Caren Sureth-Sloane \\ University of Paderborn \\ Paderborn / Germany \\ caren.sureth@upb.de
}

We are grateful for helpful comments by Petter Bjerksund, Michael Ebert, Steinar Ekern, Jochen Hundsdoerfer, Steffen Juranek, Trond Olson, Regina Ortmann, Dirk Schindler, Guttorm Schjelderup, Sönke Sievers, André Uhde and the participants of the Annual Meeting 2016 of the Accounting Section of the German Economic Association in Berlin for valuable suggestions on an earlier draft. The usual disclaimer applies. 


\section{Does Capital Tax Uncertainty Delay Irreversible Risky Investment?}

\section{Introduction}

Tax uncertainty is often claimed to be harmful for investments. Tax systems in most jurisdictions include profit and capital taxation. Property, wealth and inheritance taxes are prominent examples of capital taxes. For several reasons capital taxes in particular contribute to tax uncertainty. A survey of 830 tax and finance executive in 25 jurisdictions (EY 2014) shows that tax practitioners are particularly concerned about tax uncertainty:

“... $85 \%$ of US-headquartered companies report they are experiencing more risk or uncertainty around tax legislation or regulation than they were two years ago ... $81 \%$ of all companies surveyed agreed or strongly agreed that tax risk and controversy will become more important for their companies in the next two years. ... $82 \%$ of all companies surveyed believe their tax function has significant or adequate involvement in the general business strategy and planning process."

As both tax risk in general and capital taxation are often claimed to be harmful for investment (for empirical evidence see Dye, McGuire, and Merriman 2001, Allee, Lynch, Petroni, and Schroeder 2015, Hoppe, Maiterth, and Sureth 2016) and are expected to delay investment activities, we analyze the investment effects of capital tax uncertainty. Thus, we address the research question: How does uncertainty over (anticipated) capital tax payments affect investment timing decisions?

Capital tax uncertainty already exists if a tax reform discussion takes place. One prominent example is the OECD action plan to curb tax base erosion and profit shifting (BEPS). The OECD has recently published recommendations on how to determine the value of intellectual property (IP) in a digital economy (OECD 2015a, Action 1). However, if IP is subject to capital tax, neither do these recommendations answer all open valuation 
questions, nor do taxpayers know how the countries will implement these rules into their national tax codes. As the share of IP in a company's overall wealth is growing, so does capital tax uncertainty.

Furthermore, capital tax uncertainty arises from the unclear outcome of a future tax audit, which is difficult to predict as tax issues and tax law can be interpreted differently by taxpayers, fiscal authorities, tax auditors and tax courts. As tax laws are often too complicated to be anticipated in detail, taxpayers may use simplified models of capital tax bases in their investment decisions. Moreover, prospective investment projects sometimes only provide relatively weak tax facts, which contributes to a high level of tax uncertainty (for empirical evidence see Mills, Robinson, and Sansing, 2010; Lisowsky, Robinson, and Schmidt, 2013). Whereas these types of tax uncertainty are not capital tax-specific, any type of capital or property tax requires recognition and valuation of the respective assets, which involves considerable uncertainty. Thus, property and wealth taxation especially suffer from valuation risk and often require single case assessments. Whenever the market value of "capital" cannot be derived from observable prices of recent sales, taxpayers and fiscal authorities have to estimate the market value. The estimation of the value of a firm in this context is particularly challenging as the cash flow that arises from entrepreneurial and business activities is usually random (Müller, 2014). Furthermore, tax legislators often introduce various different valuation methods and create tax base assessment uncertainty, which contributes to total uncertainty. In summary, capital tax uncertainty exposure is typically high and realized capital tax payments often appear random from an ex ante perspective.

Despite the claim that capital taxes are harmful, we observe repeated calls for increases in capital taxes such as the (re-) introduction of a general wealth tax (for example, IMF 2013, IMF 2014, Piketty 2014) or an increase in taxes on specific assets, such as real estate. This is because capital taxes are often considered superior to profit taxation in curbing tax evasion and serve both efficiency and equality aims. Although several coun- 
tries abolished capital taxation during the 1990s and 2000s, there are animated political debates on capital taxation for distributional and fiscal purposes, especially in industrialized countries. The following table lists selected countries that are currently discussing or have recently discussed a (re-)introduction of a wealth tax or have conducted a wealth tax reform.

\begin{tabular}{|c|c|c|c|}
\hline Country & trends in wealth taxation & wealth tax in place & reforms since 2004 \\
\hline Austria & discussion since 2010 & no & \\
\hline China & discussion in 2015 & no & \\
\hline France & increase since 2012 & max. $1.5 \%$ (individual) & 3 \\
\hline Germany & discussion since 2013 & no & \\
\hline Greece & discussion in 2015 & no & \\
\hline Hungary & discussion since 2010 & no & \\
\hline Iceland & $\begin{array}{l}\text { abolition in } 2006 \\
\text { reintroduction in } 2010, \text { abolition in } 2012\end{array}$ & no & 2 \\
\hline India & abolition in 2015 & no & 3 \\
\hline Luxembourg & reintroduction in 2014 & $0.5 \%$ (corporate) & 2 \\
\hline Norway & ongoing discussion & max. $0.7 \%$ (individual) & 3 \\
\hline Netherlands & deemed income tax (box 3 ) & $30 \%$ of a deemed $4 \%$ return & \\
\hline Spain & abolition in 2007, reintroduction in 2012 & max. $2.5 \%$ (individual) & 5 \\
\hline Sweden & abolition 2007 & no & \\
\hline Switzerland/Zurich & $\begin{array}{l}\text { discussion on abolition or decrease } \\
\text { in some cantons since } 2007\end{array}$ & $\begin{array}{l}\text { max. } 0.657 \% \text { (individual) } \\
0.164 \% \text { (corporate) }\end{array}$ & 3 \\
\hline United Kingdom & discussion since 2012 & no & \\
\hline
\end{tabular}

Table 1: Wealth tax discussions and wealth tax reforms in selected OECD and OECD key partner countries from 2004 to 2016

Sources: BMF (2016), Deloitte (2004-2015), EY (2015), IBFD (2016), KPMG (2004-2015), PwC (2004-2015).

Notes: Wealth taxes on selected property, like taxes on vehicles, real estate, etc. are not included in this table. Wealth tax discussions and reforms have been considered since 2004.

The composition of total capital tax revenues varies substantially across countries. Although wealth taxes are highly topical in many jurisdictions' tax reform discussions, wealth taxes, as the most general form of capital taxes, play a rather minor role in countries' overall capital tax revenues. Nevertheless, capital taxes, especially asset-specific taxes, such as real estate taxes and property taxes, contribute significantly to public revenues, as can be observed in Figure 1. For example, the share of property taxes exeeds 
$10 \%$ of total tax revenues in Canada, Korea, the United Kingdom and the United States (OECD 2015b).

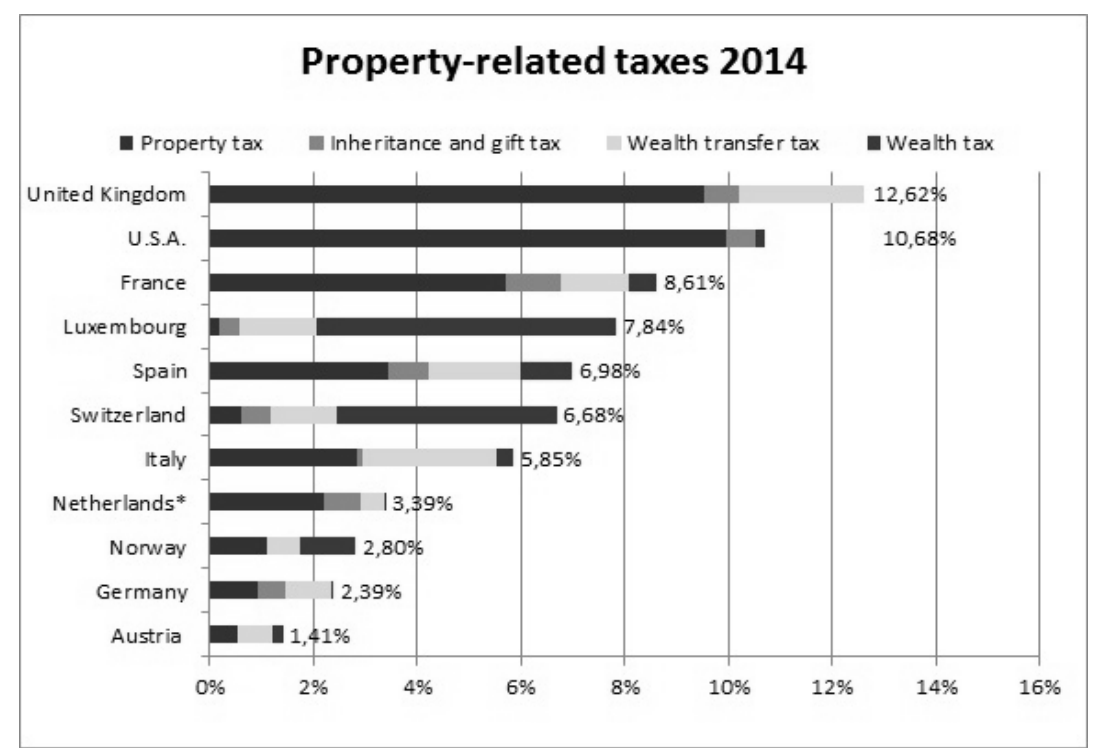

Figure 1: Capital tax revenues in different OECD countries Sources: OECD Revenue Statistics (2015b)

Obviously, even in those countries that do not levy a general wealth tax, capital taxes are important. However, some public economists raise doubts about the effectiveness of capital taxes and suspect that capital taxation could depress investment, lead to capital flight and cause efficiency costs (for example, Auerbach and Hassett 2015). ${ }^{1}$ This in turn could induce even lower total tax revenues than without capital taxation.

Against this background it is important to understand the investment effects of stochastic capital taxes at the micro level in a partial equilibrium setting. Our results are supposed to serve as a foundation for estimations of the benefits and costs of capital taxes and should be embedded in a general equilibrium model in future research. In the following, we investigate the impact of stochastic capital taxation and the inherent tax risk on the

\footnotetext{
${ }^{1}$ The effects of wealth taxes have been controversally discussed in previous years. See, e.g., Balogh (1964), Stiglitz (1969), Mieszkowski (1972), Thurow (1972), Bentick (1979), Mills (1981), Brennan and Nellor (1982), Michalos (1988), Bird (1991), Burbidge (1991), Davies (1991), Mintz (1991), and Kocherlakota (2005).
} 
timing of risky investment from a decision-maker's perspective. Our model assumes that an investor may either invest immediately or postpone their investment. We regard the time of investment as an appropriate proxy for an investor's willingness to carry out risky projects. In this sense our paper does not follow the Domar-Musgrave approach but represents a real options paradigm.

Our results indicate that investors who carry out risky investments are sensitive towards capital tax risk. We find that capital tax uncertainty, especially valuation risk, affects investment decisions, even under risk neutrality. We identify conditions that induce apparently paradoxical investment effects, meaning counterintuitive results. In contrast to well-known findings in portfolio selection models, based on Domar and Musgrave (1944), paradoxical effects in our model may arise in the absence of risk aversion. These effects can be attributed to the impact of taxes on the value of flexibility rather than portfolio-related effects. Surprisingly, we find that if a tax regime is characterized by a low level of capital tax uncertainty, an increase in tax volatility, caused, for example, by intensified tax reform discussions, may accelerate investments. Furthermore, high-growth investments are likely to be postponed if they experience a capital tax cut. However, if capital tax uncertainty is already high, further increases of uncertainty tend to delay investment. The magnitude of this effect depends on whether or not the capital tax is asset-specific. Thus, broadening the capital tax base tends to accelerate investment for small volatilities and to delay investment for large volatilities. Overall, it is ambiguous whether capital taxes that are limited to specific assets, such as real estate are less likely to delay investment than a general wealth tax.

Our findings can be regarded as the lower bound of potential effects to be expected under risk aversion and thus suggest that capital tax uncertainty is likely to be even more relevant under risk aversion. Our results indicate that capital tax risk can be substantial and thus must not be neglected. 
Our model is the first to study the investment timing effects of capital tax uncertainty, in particular of capital valuation uncertainty under conditions of irreversibility. We use a general capital tax as a representative for different types of capital taxes such as taxes on real estate, individual wealth taxes, and taxes on business property, etc. As some countries also levy capital taxes at the corporate level, ${ }^{2}$ our approach can also be interpreted as a study of the impact of corporate-level capital taxes on corporate investments.

The remainder of the paper is organized as follows. After a review of the literature in the next section, we introduce the model in section 3 and determine the critical investment threshold that indicates whether or not to implement a risky project. In section 4 we investigate, which parameters determine investment timing and under what conditions apparently paradoxical timing effects are likely. Section 5 summarizes and draws conclusions.

\section{Literature Review}

Prior studies on the welfare effects of uncertain tax policy indicate that removing all uncertainty about future tax policy may lead to considerable welfare gains. For example, Skinner (1988) estimates a welfare gain of 0.4 percent of national income for the United States. Bizer and Judd (1989) highlight that the potential efficiency costs of random tax policy strongly depend on the characteristics of the random tax instrument. Other studies show that tax policy uncertainty can be socially useful (Alm 1988). Although we do not aim to draw conclusions about the aggregate effects on investment, tax revenues and wealth distribution, these findings motivate us to scrutinize the effects of stochastic capital taxation from a micro-level perspective. Using an analytical model we find that the arising distortions with respect to investment decisions are multifold. These distortions are not only highly dependent on the tax risks involved, but also dependent on the economic

\footnotetext{
${ }^{2}$ Countries with wealth taxation at the corporate level are, for example, Luxembourg and most Swiss cantons.
} 
and tax environment.

Although there are means to shield taxpayers against some types of tax risks, usually tax uncertainty cannot be resolved completely. To reduce the tax risk, taxpayers may request ex ante rulings or letters of expertise from tax advisors or ask the tax authority to provide a real-time audit (Beck and Lisowsky 2014) or even purchase an insurance against tax risk (Logue 2005). Unfortunately, these instruments are typically either not available, not feasible, too complicated, too imperfect in resolving uncertainty or too expensive (Givati 2009 and De Simone, Sansing, and Seidman 2013). Moreover, recent research indicates that instruments such as advance tax rulings will often not be requested by taxpayers who are exposed to high tax uncertainty (Diller, Kortebusch, Schneider, and Sureth 2016). All this implies that capital tax assessments typically involve a significant amount of tax risk that arises from the estimation procedures and from unpredictable outcomes of tax audits.

Prior empirical research, such as Edmiston (2004), provides evidence for the negative impact of tax uncertainty on investments. However, other theoretical and empirical investigations indicate that (profit or income) tax uncertainty could encourage or discourage investment and risk taking (Hassett and Metcalf, 1999). For example, Beck and Jung (1989) investigate the impact of profit tax uncertainty on investment behavior and reported income. They analytically demonstrate that greater tax liability uncertainty may either increase or decrease reported income. Furthermore, Agliardi (2001) and Niemann (2011) identify ambiguous effects of profit tax uncertainty on investment decisions in a real option setting. Niemann (2011) also shows that if tax uncertainty is small compared to cash flow uncertainty, and if both stochastic processes are positively correlated, increased tax uncertainty may also accelerate investment. Jacob, Wentland, and Wentland (2016) test empirically whether firm-specific profit tax uncertainty affects firms' timing of large investments. They find that firms with high (low) tax rates face an upside (downside) tax risk and accelerate (delay) investments upon an increase in tax uncertainty. Evidently, tax uncertainty distorts investment behavior in a rather unpredictable way. Surprisingly, 
none of these studies accounts for capital taxes or capital tax uncertainty.

Among the few studies on capital taxes and their impact on investment decisions Dye, McGuire, and Merriman (2001) find evidence that high property tax rates lead to significantly slower growth rates. Craft and Schmidt (2005) find evidence for significant decreases in vehicular capital after changes in vehicle property taxes. Accordingly, Allee, Lynch, Petroni, and Schroeder (2015) find significant sensitivities of petroleum refineries in their crude oil inventories when investors are subject to a personal property tax. Hansson (2008) analyzes the abolishment or suspension of general wealth taxation in Austria in 1994, in Denmark in 1997, in Germany in 1997, and in the Netherlands in 2001. She finds evidence for a small but perceptible impact of wealth tax abolishment on entrepreneurial activity. Van Wijnbergen and Estache (1999) examine the impact of a minimum asset tax, which is similar to a wealth tax, on high-risk firms using an option pricing approach and a Monte Carlo simulation with Brazilian data. They find that high-risk firms do not seem to be hit harder by the underlying tax. Under specific conditions the introduction of the minimum asset tax may even lower the marginal effective tax rates. Their results are in line with the wealth tax paradox that has been elaborated under certainty in Sureth and Maiterth (2008) and under uncertainty in Niemann and Sureth-Sloane (2015). As a consequence, the existing empirical studies only allow us to draw mixed conclusions. All of them disregard capital tax uncertainty.

To understand the potential investment effects of stochastic capital taxation, this stream of literature has to be extended with respect to capital tax uncertainty. This is particularly important, as capital taxation in existing tax systems turns out not to be (perfectly) correlated with profit taxation. While the effects of stochastic profit (or income) taxation at least to some extent have been investigated (Agliardi 2001, Niemann 2011, Diller, Kortebusch, Schneider, and Sureth 2016), the effects of stochastic capital (or property) taxation have not yet been analyzed under conditions of cash flow uncertainty and irreversibility. 
Our results highlight the relevance of capital tax risk for investment decisions and provide novel insights that contribute to the current discussion on re-introducing or extending capital taxation. Capital tax risk may delay high-risk investment, especially as a reaction to a newly introduced capital tax. To reduce unintended consequences of uncertain tax policy, politicians and fiscal authorities should avoid too high levels of capital tax uncertainty, which are likely to hinder innovative investment activities.

\section{$3 \quad$ Model setup}

Our model of investment is based on the framework provided by Dixit and Pindyck (1994) that is frequently used for the analysis of tax effects under uncertainty and irreversibility. ${ }^{3}$ In line with this body of literature we assume that a risk neutral investor ${ }^{4}$ has the option to invest in an infinitely-lived real investment project that yields stochastic cash flows. For reasons of mathematical simplicity the option to invest is considered perpetual and inherent to the investment opportunity. We abstract from acquired options. The return on investment is subject to profit taxation. Moreover, the investment project can be subject to stochastic capital taxation. The investor uses individual calculus for valuation of both the project and the option to invest. We do not need to assume that the spanning property holds, i.e., liquid markets for the assets do not necessarily exist. Thus, our approach is more general and also captures investment projects that cannot be replicated by traded assets. As long as the option to invest is not exercised, available funds yield the risk-free capital market rate. If the option to invest is exercised, the investor gives up all flexibility and pays the acquisition cost for the project. There is no obligation to invest within finite time. If the project conditions do not turn out to be sufficiently favorable,

\footnotetext{
${ }^{3}$ See, e.g., Niemann (1999), Sureth (2002), Panteghini (2004, 2005), Alvarez and Koskela (2008), Gries, Prior and Sureth (2012).

${ }^{4}$ In contrast to research following Domar and Musgrave (1944), who assume risk averse investors optimizing their mix of risk-free and risky investments, in our analysis uncertainty-induced distortions of the timing of risky investments arise even under risk neutrality. Thus, we add two issues to the literature that arise from capital tax uncertainty and have not been addressed so far: unexpected timing effects of random capital taxation and the distortive power of stochastic capital taxation even under risk neutrality.
} 
the investment project can be infinitely postponed. We assume that the project is entirely equity-financed to separate the tax effects on investment from the financing effects.

When investors try to estimate the total risk of investment projects, they should be aware that operational or cash flow uncertainty is not the only source of uncertainty of such projects. Rather, investors have to regard taxation as a random process from an ex ante perspective. Integrating capital taxation as a stochastic process into investment models seems to be an appropriate method to deal with uncertainty regarding the introduction or the increase of a capital tax. It should be noted that stochastic capital taxation already influences decisions if only a discussion on tax reform takes place, even if a capital tax is currently not (and possibly never) levied.

Since it is the aim of this paper to analyze the combined effects of profit and capital taxation on investment timing, the tax treatment of the investment project, the option to invest, and the default alternative (i.e., wait and see) must be properly defined. We consider only one level of taxation. This assumption means that the investor is either a sole proprietor, partner in a private partnership or corporation that neglects shareholder taxation.

As long as the investor waits and does not (yet) invest, they earn the risk-free pretax interest rate $r$ that is subject to the tax rate $\tau_{r}$. In accordance with tax law in several countries the tax rate on financial income $\tau_{r} \in[0,1[$ can differ from the general profit tax rate. ${ }^{5}$ Financial assets like bank accounts or bonds that yield interest income can be (and often are) subject to an additional capital taxation at the rate $\tau_{\omega} \in[0,1[$. The variable $\gamma \in[0,1]$ denotes the fraction of these financial assets that is subject to capital taxation. Thereby, we are able to model capital taxes that are asset-specific and partially or completely exempt financial assets from capital taxation. By defining $\gamma$ as deterministic, we assume a deterministic capital tax base of financial assets. As a result,

\footnotetext{
${ }^{5}$ Examples are countries such as Austria, Croatia, or Germany.
} 
the risk-free discount rate after taxes $r_{\tau}$ that captures the default alternative is defined as

$$
r_{\tau}=\left(1-\tau_{r}\right) r-\gamma \tau_{\omega}>0
$$

We assume that the after-tax discount rate is strictly positive. Otherwise, present values could reach economically meaningless infinite values. ${ }^{6}$

The parameter $\gamma$ also permits us to model different types of capital taxes and to analyze their possible different investment effects. If only special assets like real estate are subject to tax while financial assets are exempt from this type of capital tax, the parameter is zero, $\gamma=0$. By contrast, if a general wealth tax including all types of assets is considered, financial assets are fully taxable and thus $\gamma=1$. As a consequence, broadening (narrowing) the capital tax base can be represented by increasing (decreasing) the parameter $\gamma$.

If the investor decides to exercise the option to invest and acquires the investment project, they lose any further timing flexibility and are bound to the project until infinity. If the project is in place, its only benefits consist of the future cash flows. Stochastic operating cash flows are subject to profit taxation that can also be regarded as a stochastic process. Uncertainty of profit tax payments arises from random tax rates or random tax bases. In order to focus on the effects of capital taxation we do not model operating cash flows, profit tax rates, and profit tax bases as separate stochastic processes. Instead, we summarize operating cash flows less profit tax payments to a single stochastic process $\pi(t) .^{7}$

\footnotetext{
${ }^{6}$ Although negative nominal interest rates sometimes do exist, we leave this observation as a problem for future research in finance. However, the combination of low interest rates and high wealth taxes may lead to negative $r_{\tau}$. E.g., this is the case in Norway, where in 2015 interest rates of $0.5 \%$ meet a wealth tax on financial assets of $1 \%$.

${ }^{7}$ This assumption implies that deductions for income tax purposes are only implicitly captured. However, the properties of the income tax base under uncertainty have been extensively analyzed in the literature. See, e.g., Niemann (1999), Sureth (2002), Niemann and Sureth (2004, 2005). For stochastic income tax rates see Niemann (2004). If we wanted to model cash flow uncertainty and profit tax uncertainty separately, we would need to introduce two stochastic processes and an additional stochastic process for wealth taxation. Although this might be fruitful in future research, we decided to focus on the effects from stochastic capital taxation and thus summarize operating cash flow uncertainty and profit tax uncertainy to a single process.
} 
The capital tax base is determined by the value of tangible and intangible assets, such as machinery, plant, real estate, vehicles, corporate stocks, patents etc., which are attributable to the investment project. The capital tax has to be paid out of the preliminary after-tax cash flow $\pi(t)$. We assume that the capital tax base at time $t$, which is denoted by $W(t)$, is also a stochastic process. This assumption reflects real-world tax bases quite well if the capital tax base is defined as the "fair value", i.e., the market value of the assets attributable to an investment project. Here, cash flow uncertainty leads to capital tax base uncertainty whenever the tax base is correlated with the stochastic cash flows or if a portfolio of various valuation approaches is applicable. Moreover, even if the assessment of the assets and herewith the capital tax base does not involve any uncertainty because the legislator has defined a clear valuation procedure without any discretion in valuation, uncertainty may arise, for example, from unclear definitions of taxable tangible and intangible assets. This implies uncertainty with respect to the interpretation by the fiscal authorities and thereby the outcome of a future tax audit.

In contrast to profit taxation, we model the capital tax rate and the capital tax base separately, because the capital tax rate might also affect the after-tax discount rate. For reasons of mathematical simplicity, the capital tax rate $\tau_{\omega}$ (like the tax rate on financial income $\tau_{r}$ ) is considered deterministic and constant. In the following, capital tax uncertainty is completely captured in the random capital tax base. This approach primarily addresses the uncertainty that arises from asset valuation. As a result, the total after-tax cash flow $\pi_{\tau}(t)$ is defined as

$$
\pi_{\tau}(t)=\pi(t)-\tau_{\omega} W(t)
$$

Since the investor is risk neutral the value of the project in place $V$ at time $t=0$ is defined as the expected net present value

$$
V_{\tau}=V_{\tau}(0)=E\left[\int_{0}^{\infty} \pi_{\tau}(t) e^{-r_{\tau} t} d t\right]
$$


For further results the cash flow process and the capital tax base process have to be defined. In accordance with prior literature (see Niemann 2011) we assume that the operating cash flow after profit taxes $\pi$ follows an exogenously given arithmetic Brownian motion

$$
d \pi=\alpha_{\pi} d t+\sigma_{\pi} d z_{\pi}
$$

with $\alpha_{\pi}$ as the expected growth of cash flows after profit taxes, $\sigma_{\pi}$ as the standard deviation, and $d z_{\pi}$ as increment of a standard Wiener process. In contrast to the geometric Brownian motion that is frequently used in asset pricing and that always takes positive values, an arithmetic Brownian motion allows us to describe profits as well as losses as possible realizations of the random walk. As a more formal argument in favor of an arithmetic Brownian motion it should be noted that the sum or the difference of two arithmetic Brownian motions is itself an arithmetic Brownian motion. A similar relation does not hold for a geometric Brownian motion or other stochastic processes. ${ }^{8}$ To compute the project value analytically it is further necessary to use a stochastic process that permits closed-form expected values. The capital tax base $W$ also follows an exogenously given arithmetic Brownian motion. We abstract from capital tax jumps. The assumption of an arithmetic Brownian motion implies that positive as well as negative values for capital tax purposes are possible. The capital tax base may or may not be a function of past cash flows. This unsigned tax base reflects that deductions, such as provisions, liabilities, and reserve liabilities can be attributable to an investment project. We assume symmetric capital taxation of positive and negative values.

$$
d W=\alpha_{\omega} d t+\sigma_{\omega} d z_{\omega}
$$

with $\alpha_{\omega}$ as the expected growth of the capital tax base, $\sigma_{\omega}$ as the associated standard deviation, and $d z_{\omega}$ as increment of a standard Wiener process. The growth and volatility parameters $\alpha_{\omega}$ and $\sigma_{\omega}$ may significantly differ from $\alpha_{\pi}$ and $\sigma_{\pi}$ of the after-tax cash flow

\footnotetext{
${ }^{8}$ Our approach implicitly assumes an immediate and complete loss offset for tax purposes. This means that we abstract from loss offset restrictions for reasons of mathematical simplicity.
} 
process. It should be noted that the default alternative (i.e., wait and see) generates deterministic cash flows (i.e., risk-free interest income) and a deterministic capital tax base.

The capital tax base process of the risky project can be correlated with the first process, the cash flow process

$$
E\left[d z_{\pi} d z_{\omega}\right]=\rho d t
$$

where $\rho \in[-1,1]$ denotes the instantaneous correlation coefficient of both arithmetic Brownian motions. A perfect positive correlation $(\rho=1)$ means that the project value for capital tax purposes perfectly reflects the expected after-tax present value of the project. This assumption is closely related to the existence of complete markets for the investment project under consideration. Uncorrelated processes $(\rho=0)$ mean that the capital tax base is independent of the expected present value of the project. This assumption corresponds to the arbitrary valuation of real estate in several jurisdictions. ${ }^{9}$ Negative correlations $(\rho<0)$ are rather implausible because they would involve deliberately procyclical capital taxation. ${ }^{10}$ To depict real-world types of capital taxation, we focus on the cases of uncorrelated or non-perfect positive $(0 \leq \rho<1)$ correlations. ${ }^{11}$

Being the difference of two arithmetic Brownian motions, the after-tax cash flow $\pi_{\tau}=$ $\pi-\tau_{\omega} W$ is itself an arithmetic Brownian motion that can be represented by

$$
d \pi_{\tau}=\alpha_{\tau} d t+\sigma_{\tau} d z
$$

with $\alpha_{\tau}=\alpha_{\pi}-\tau_{\omega} \alpha_{\omega}$ as the growth parameter of the total after-tax cash flow, $\sigma_{\tau}=$ $\sqrt{\sigma_{\pi}^{2}+\tau_{\omega}^{2} \sigma_{\omega}^{2}-2 \rho \tau_{\omega} \sigma_{\pi} \sigma_{\omega}}$ as the combined standard deviation, ${ }^{12}$ and $d z$ also the increment

\footnotetext{
${ }^{9}$ As an example, the tax value of real estate in Austria or in Germany ("Einheitswert") is only weakly related to market values.

${ }^{10} \rho$ can also be interpreted as a parameter that captures the tax audit risk. If the fiscal authorities audit procyclically, $\rho>0$ indicates an increase in tax audit risk with increased cash flow. If they audit countercyclically $\rho<0$ implies increased tax audit risk.

${ }^{11}$ To generalize our setting we do not assume a strict functional relation of cash flows and the capital tax base. For correlations of $\rho=1$ the wealth tax can also be intepreted as a (notional) profit tax.

${ }^{12}$ We use the standard deviation to model volatility. This operationalization is in line with a large
} 
of a standard Wiener process. If the stochastic processes are perfectly correlated $(\rho=1)$, total volatility simplifies to $\sigma_{\tau}=\sigma_{\pi}-\tau_{\omega} \sigma_{\omega}$. If capital tax base uncertainty is the only source of uncertainty $\left(\sigma_{\pi}=\rho=0\right)$, total volatility amounts to $\sigma_{\tau}=\tau_{\omega} \sigma_{\omega}$.

The assumption of arithmetic Brownian motions permits to write the expected after-tax cash flow at time $t$ as

$$
E\left[\pi_{\tau}(t)\right]=\pi_{\tau}(0)+\alpha_{\tau} t=\pi_{\tau}^{0}+\left(\alpha_{\pi}-\tau_{\omega} \alpha_{\omega}\right) t
$$

Consequently, the project value is

$$
V_{\tau}=E\left[\int_{0}^{\infty}\left[\pi_{\tau}^{0}+\left(\alpha_{\pi}-\tau_{\omega} \alpha_{\omega}\right) t\right] e^{-r_{\tau} t} d t\right]=\frac{\pi_{\tau}^{0}}{r_{\tau}}+\frac{\alpha_{\tau}}{r_{\tau}^{2}} .
$$

Given the value of the investment project, the value of the option to invest can be determined. Since the investor can only decide between waiting and exercising the option, the decision variable is binary and it is easily possible to determine the optimal investment behavior. We will start with the waiting region in which the option is kept alive. As we do not restrict our analysis by assuming a specific initial value of the capital tax base at the time of decision making, we implicitly restrict the initial values such that the expected after-tax present value of the project in the waiting region is below the critical investment threshold, which is still to be determined.

The optimal transition to the exercise region will be modeled by boundary conditions. We use dynamic programming to determine the option value. ${ }^{13}$

The option to invest does not generate any cash flows. In principle, an option could be relevant for profit tax as well as capital tax purposes. For example, the increase or decrease body of literature on different types of volatility. For recent studies that refer to tax volatility issue in accounting see, e.g., De Simone and Stomberg (2013), Jacob and Schütt (2013), McGuire, Neuman and Omer (2013) and Neuman, Omer and Schmidt (2016), Guenther, Matsunaga and Williams (2016).

${ }^{13}$ For a comparison of dynamic programming and contingent claims analysis and the resulting tax effects see Niemann and Sureth $(2004,2005)$. 
of the option value could be taxable or tax-deductible respectively. ${ }^{14}$ Alternatively, the option value could be subject to capital taxation. However, tax systems in the real world do not recognize mere business opportunities as taxable assets. Therefore, we neglect tax consequences of the option to invest that might be relevant in ideal tax systems. Thus, the option's after-tax cash flow equals zero in the case considered here.

As long as the option is kept alive, its only benefit is the expected increase in value. The resulting equilibrium condition implies that the owner of the option expects an instantaneous return that equals the after-tax risk-free rate over an infinitesimal time interval $d t$

$$
E\left[d F_{\tau}\right] \stackrel{!}{=} r_{\tau} d t
$$

Application of Itô's lemma to the stochastic differential $d F_{\tau}$ and further transformation yields the ordinary differential equation ${ }^{15}$

$$
\frac{1}{2} \sigma_{\tau}^{2} \frac{d^{2} F_{\tau}}{d \pi_{\tau}^{2}}+\alpha_{\tau} \frac{d F_{\tau}}{d \pi_{\tau}}-r_{\tau} F_{\tau} d t=0
$$

with the solution

$$
F_{\tau}\left(\pi_{\tau}\right)=A e^{\beta \pi_{\tau}}, \quad \text { with } \beta_{\tau}=-\frac{\alpha_{\tau}}{\sigma_{\tau}^{2}}+\sqrt{\left(\frac{\alpha_{\tau}}{\sigma_{\tau}^{2}}\right)^{2}+\frac{2 r_{\tau}}{\sigma_{\tau}^{2}}}>0
$$

where $A>0$ is a constant to be determined. From $A, \beta_{\tau}>0$ it is obvious that $F_{\tau}(-\infty)=$ 0 holds. This condition means that an option on an underlying with infinite negative value is valueless.

The solution of the investment problem describes the investment threshold at which it is optimal to exercise the option immediately. To derive this solution two free boundary conditions are needed. The value matching condition requires that the project's benefits

\footnotetext{
${ }^{14}$ Acquired real options like exploration rights, e.g., are depreciable under most tax regimes. Depreciation deductions on the option to invest are necessary in some neutral tax systems. See Niemann (1999, pp. 57, 61). Although real-world tax systems only account for depreciations on acquired options, overall depreciation on (also non-acquired) options would be in line with fair value reasoning.

${ }^{15}$ Since the option to invest is perpetual, the time derivative vanishes here.
} 
and hence its expected present value must equal its costs, comprising the acquisition cost and the abandoned option value, at the point of transition

$$
V_{\tau}\left(\pi_{\tau}^{*}\right)-1 \stackrel{!}{=} F_{\tau}\left(\pi_{\tau}^{*}\right)
$$

For reasons of simplicity, the acquisition costs are normalized to unity: $I_{0}=1$. The smooth pasting condition requires the identity of marginal benefits and marginal costs at the critical threshold

$$
\frac{d V_{\tau}\left(\pi_{\tau}^{*}\right)}{d \pi_{\tau}} \stackrel{!}{=} \frac{d F_{\tau}\left(\pi_{\tau}^{*}\right)}{d \pi_{\tau}}
$$

Substituting and further transformation yields the critical investment threshold ${ }^{16}$

$$
\pi_{\tau}^{*}=r_{\tau}-\frac{\alpha_{\tau}}{r_{\tau}}+\frac{1}{\beta_{\tau}}
$$

Equation (15) can be interpreted as follows. The expected present value of after-tax cash flows (eq. 9) must reach the acquisition costs $I_{0}=1$ of a project plus a flexibility premium $\frac{1}{\beta_{\tau} r_{\tau}}>0$ to cover the value of the option which is lost due to exercise. ${ }^{17}$ The variancedependent flexibility premium implies that even risk neutral investors take uncertainty into account for investment timing decisions.

\section{Investment timing effects of stochastic capital tax- ation}

The impact of stochastic capital taxation on investment timing can be determined by computing the partial derivatives of the critical investment threshold $\pi_{\tau}^{*}$ with respect to the different capital tax parameters. These parameters are

- expected growth of the capital tax base $\alpha_{\omega}$,

- correlation of capital tax base and operating cash flow after profit taxes $\rho$,

\footnotetext{
${ }^{16}$ For a similar critical investment threshold without wealth taxation see Niemann (2011), p. 9.

${ }^{17}$ For the interpretation of the flexibility premium in scenarios with and without uncertainty under irreversibility see Gries, Prior and Sureth (2012), pp. 530-532.
} 
- volatility of the capital tax base $\sigma_{\omega}$,

- taxable fraction of financial assets $\gamma$ (capital taxation of the default alternative), and

- capital tax rate $\tau_{\omega}$.

In contrast to traditional (expected) NPV calculations the critical investment threshold in a real options model takes into account that taxation not only affects the cash flows from an investment project, the default alternative as represented by the after-tax interest rate and (potentially) the initial outlay, but also the value of timing flexibility, i.e., the option to invest. Thus, the tax effect on the option value should be considered when analyzing variations of tax parameters. Tax effects on option values are one of the reasons why results of real options models differ from those of portfolio selection models following Domar and Musgrave (1944).

Proposition 1 Increasing the expected growth of the capital tax base $\alpha_{\omega}$ unambiguously increases the critical investment threshold.

Proof. The algebraic sign of the partial derivative is always positive:

$$
\frac{\partial \pi_{\tau}^{*}}{\partial \alpha_{\omega}}=\underbrace{\frac{\partial \pi_{\tau}^{*}}{\partial \alpha_{\tau}}}_{<0} \cdot \underbrace{\frac{\partial \alpha_{\tau}}{\partial \alpha_{\omega}}}_{<0}=\frac{\alpha_{\tau}-\sqrt{\alpha_{\tau}^{2}+2 \sigma_{\tau}^{2} r_{\tau}}}{2 r_{\tau} \sqrt{\alpha_{\tau}^{2}+2 \sigma_{\tau}^{2} r_{\tau}}}\left(-\tau_{\omega}\right)>0 .
$$

This result is intuitive (normal effect). The higher the expected growth of the capital tax base, the higher the expected present value of capital tax payments and hence the critical investment threshold. Consequently, higher growth rates of the capital tax base tend to delay investment. Stated differently, the tax legislator can accelerate investment by permitting depreciation for capital tax purposes $\left(\alpha_{\omega}<0\right)$ rather than by prescribing valuation approaches that lead to tax values increasing over time. 
Proposition 2 Increasing the correlation of the capital tax base and cash flows $\rho$ unambiguously reduces the critical investment threshold.

Proof. The algebraic sign of the partial derivative is always negative.

$$
\frac{\partial \pi_{\tau}^{*}}{\partial \rho}=\underbrace{\frac{\partial \pi_{\tau}^{*}}{\partial \sigma_{\tau}}}_{>0} \cdot \underbrace{\frac{\partial \sigma_{\tau}}{\partial \rho}}_{<0}=\frac{-\tau_{\omega} \sigma_{\omega} \sigma_{\pi}}{\sqrt{\alpha_{\tau}^{2}+2 \sigma_{\tau}^{2} r_{\tau}}}<0
$$

Thus, a higher correlation of the stochastic processes reduces total volatility and hereby accelerates investment (normal effect). This result permits an immediate tax policy conclusion. A capital tax base that is closely related to fair values as measured by the expected after-tax present value of a project (i.e., $\rho \rightarrow 1$ ) accelerates investment compared to an arbitrary valuation for capital tax purposes (i.e., $\rho=0$ ). We use the notion of fair value in the sense of market valuation. We do not imply fair values as defined in financial accounting. Examples of the consequences can be seen in versions of the real estate tax that have a weak association of tax base and market value. These types of taxes tend to delay real estate investment compared to a fair value approach.

Proposition 3 Increasing the volatility of the capital tax base $\sigma_{\omega}$ either increases or reduces the critical investment threshold.

Proof. The partial derivative of $\pi_{\tau}^{*}$ with respect to $\sigma_{\omega}$ can take either algebraic sign:

$$
\frac{\partial \pi_{\tau}^{*}}{\partial \sigma_{\omega}}=\underbrace{\frac{\partial \pi_{\tau}^{*}}{\partial \sigma_{\tau}}}_{>0} \cdot \underbrace{\frac{\partial \sigma_{\tau}}{\partial \sigma_{\omega}}}_{\gtrless 0}=\frac{\tau_{\omega}^{2} \sigma_{\omega}-\rho \tau_{\omega} \sigma_{\pi}}{\sqrt{\alpha_{\tau}^{2}+2 \sigma_{\tau}^{2} r_{\tau}}} .
$$

An increase in total volatility increases the critical investment threshold (normal effect). This result is consistent with traditional option pricing theory, because increased (total) volatility increases option values without changing expected cash flows of the project or 
the after-tax discount rate. However, increasing the volatility of the capital tax base $\sigma_{\omega}$ has an ambiguous impact on total volatility $\sigma_{\tau}$ :

$$
\frac{\partial \sigma_{\tau}}{\partial \sigma_{\omega}}\left\{\begin{array}{l}
> \\
= \\
<
\end{array}\right\} 0 \Leftrightarrow \tau_{\omega} \sigma_{\omega}\left\{\begin{array}{l}
> \\
= \\
<
\end{array}\right\} \rho \sigma_{\pi} \quad\left\{\begin{array}{c}
\text { "normal" tax effect } \\
\text { "paradoxical" tax effect }
\end{array}\right\} .
$$

Thus, if the volatility of the capital tax base $\sigma_{\omega}$ is small compared to cash flow volatility $\sigma_{\pi}$, increased capital tax volatility $\sigma_{\omega}$ tends to reduce total volatility $\sigma_{\tau}$ and hereby accelerates investment. Although we assume risk neutrality, an effect similar to diversification emerges. This apparently "paradoxical" result holds if the correlation coefficient $\rho$ is positive and sufficiently large. By contrast, if capital tax base uncertainty is the only source of uncertainty $\left(\sigma_{\tau}=\tau_{\omega} \sigma_{\omega}>0=\sigma_{\pi}\right)$ only "normal" timing effects are possible. Normal timing effects also occur if the cash flow process and the tax base process are uncorrelated $(\rho=0)$. For a given positive correlation $\rho>0$, cash flow volatility $\sigma_{\pi}>0$ and capital tax rate $\tau_{\omega} \geq 0$, an increase of the capital tax base volatility $\sigma_{\omega}$ first yields paradoxical and then, from a critical capital tax base volatility level onward, normal tax effects.

$$
\left.\sigma_{\omega}\left\{\begin{array}{l}
> \\
= \\
<
\end{array}\right\} \frac{\rho}{\tau_{\omega}} \sigma_{\pi} \Leftrightarrow \frac{\partial \sigma_{\tau}}{\partial \sigma_{\omega}}\right|_{\rho>0, \sigma_{\pi}>0, \tau_{\omega}>0}\left\{\begin{array}{l}
> \\
= \\
<
\end{array}\right\} 0 .
$$

This result implies the following neutrality condition.

Corollary 1 Capital tax uncertainty does not affect investment timing if $\tau_{\omega} \sigma_{\omega}=\rho \sigma_{\pi}$.

Thus, if the tax legislator does not intend to influence investment timing by means of capital tax uncertainty but rather seeks for a timing neutral tax system, perfectly calibrated tax and non-tax parameters are necessary to avoid undesired effects. In actual or currently planned tax systems that are not characterized by project-specific rules, neutrality is therefore highly unlikely.

With respect to the parameters $\gamma$ and $\tau_{\omega}$ we define effects of capital taxation as "normal" if increasing capital taxation of the investment project increases the critical investment threshold and if increasing capital taxation of financial assets (default alternative) reduces 
the critical investment threshold, i.e., if $\partial \pi_{\tau}^{*} / \partial \tau_{\omega}>0$ or $\partial \pi_{\tau}^{*} / \partial \gamma<0$. Otherwise, for $\partial \pi_{\tau}^{*} / \partial \tau_{\omega}<0$ or $\partial \pi_{\tau}^{*} / \partial \gamma>0$, we call tax effects "paradoxical". ${ }^{18}$

Proposition 4 Increasing the taxable fraction of financial assets $\gamma$ either increases or reduces the critical investment threshold.

Proof. The algebraic sign of the partial derivative is ambiguous.

$$
\begin{aligned}
\frac{\partial \pi_{\tau}^{*}}{\partial \gamma} & =\frac{\partial \pi_{\tau}^{*}}{\partial r} \cdot \frac{\partial r}{\partial r_{\tau}} \cdot \frac{\partial r_{\tau}}{\partial \gamma}=\frac{\partial \pi_{\tau}^{*}}{\partial r} \cdot \frac{1}{\frac{\partial r_{\tau}}{\partial r}} \cdot\left(-\tau_{\omega}\right)=\underbrace{\frac{\partial \pi_{\tau}^{*}}{\partial r}}_{\gtrless 0} \cdot \underbrace{\frac{-\tau_{\omega}}{1-\tau_{r}}}_{<0} \\
\text { with } \frac{\partial \pi_{\tau}^{*}}{\partial r} & =\frac{1-\tau_{r}}{2 r_{\tau}^{2}}\left(\alpha_{\tau}+2 r_{\tau}^{2}-\frac{\alpha_{\tau}^{2}+\sigma_{\tau}^{2} r_{\tau}}{\sqrt{\alpha_{\tau}^{2}+2 \sigma_{\tau}^{2} r_{\tau}}}\right) .
\end{aligned}
$$

Evaluating the partial derivatives in the limiting cases $\sigma \rightarrow 0$ and $\sigma \rightarrow \infty$ yields

$$
\lim _{\sigma \rightarrow 0} \frac{\partial \pi_{\tau}^{*}}{\partial \gamma}=-\tau_{w}<0 \quad \lim _{\sigma \rightarrow \infty} \frac{\partial \pi_{\tau}^{*}}{\partial \gamma}=-\frac{\tau_{\omega}}{2 r_{\tau}^{2}}\left(\alpha_{\tau}+2 r_{\tau}^{2}-\sigma_{\tau} \sqrt{\frac{r_{\tau}}{2}}\right)=+\infty
$$

From continuity with respect to $\sigma_{\tau} \geq 0$ it follows that $\frac{\partial \pi_{\tau}^{*}}{\partial \gamma}<0$ for small volatilities and $\frac{\partial \pi_{\tau}^{*}}{\partial \gamma}>0$ for sufficiently high volatilities.

The special case of $\alpha_{\tau}=0$ further clarifies the ambiguity of effects.

$$
\left.\frac{\partial \pi_{\tau}^{*}}{\partial \gamma}\right|_{\alpha_{\tau}=0}=\tau_{\omega}\left(\sqrt{\frac{\sigma_{\tau}^{2}}{8 r_{\tau}^{3}}}-1\right)\left\{\begin{array}{l}
> \\
= \\
<
\end{array}\right\} 0 \Leftrightarrow \sigma_{\tau}^{2}\left\{\begin{array}{l}
> \\
= \\
<
\end{array}\right\} 8 r_{\tau}^{3} .
$$

Hence, the occurance of normal or paradoxical capital tax effects with respect to $\gamma$ strongly depends on the levels of the discount rate and capital tax uncertainty. For sufficiently high after-tax discount rates $r_{\tau}$ and small volatilities $\sigma_{\tau}^{2}$, normal tax effects prevail. As a consequence, for high pre-tax interest rates, real-world levels of the financial income tax rate $\tau_{r}$, and low or moderate levels of the capital tax rate $\tau_{\omega}$, the partial derivative $\partial \pi_{\tau}^{*} / \partial \gamma$ is negative, which means that increasing the taxable fraction of financial assets reduces the critical investment threshold and hence accelerates real investment. This effect is plausible, because increasing $\gamma$ does not affect cash flows from investment and only reduces

\footnotetext{
${ }^{18}$ For paradoxical income tax effects see, e.g., Niemann and Sureth (2013).
} 
the after-tax discount rate $r_{\tau}$. Therefore, the present value of the investment project $V$ increases in $\gamma$. As an additional effect of increasing $\gamma$ the lower discount rate typically reduces the option value, making immediate investment more attractive. An increased project value and a reduced option value both contribute to accelerated investment.

However, with after-tax discount rates sufficiently close to zero, increasing $\gamma$ increases the critical investment threshold so that a paradoxical capital tax effects occurs. In these cases, increasing $\gamma$ reduces the discount rate such that the expected present value of capital taxes increases relatively more than the present value of cash flows. Moreover, for low or negative growth parameters $\alpha_{\tau}$, high volatilities, and low discount rates, the critical investment threshold tends to increase with a higher taxable fraction $\gamma$ (or, equivalently, with a lower discount rate), because for these parameter combinations the option value decreases faster than the project value.

As apparently paradoxical timing effects are likely for high total volatility and/or low discount rates, the tax legislator should consider these cases and should estimate their relative impact on overall investments and thus taxable assets in the economy when deciding on which type of capital tax to implement. When a tax on special non-financial assets like real estate is already in place $(\gamma=0)$, broadening the capital tax base by increasing the taxable fraction of financial assets may induce unexpected (and unintended) investment responses when total volatility is high. A similar result can emerge when a general wealth $\operatorname{tax}(\gamma=1)$ is narrowed to a tax on special non-financial assets by reducing $\gamma$. From a tax policy perspective these possible results could be important determinants of revenues from capital taxes and indirectly also of profit tax revenues.

Corollary 2 Varying $\gamma$ always yields effects opposite to those from varying the pre-tax interest rate $r$ (see eq. (21)). 
Whereas the project value $V_{\tau}$ decreases when the interest rate increases, the option value $F_{\tau}$ may increase, decrease, or remain constant. ${ }^{19}$

The effects of varying the capital tax rate $\tau_{\omega}$ are similar to a simultaneous increase of the growth parameter $\alpha_{\omega}$ and of the default alternative parameter $\gamma$ because the capital tax rate affects the net cash flows of the investment project as well as the default alternative, represented by the after-tax interest rate $r_{\tau}$. Since Proposition 4 implies that a variation of $\gamma$ induces ambiguous timing effects, a similar result can be expected from a variation of $\tau_{\omega}$. However, this effect is mitigated by the expected increase of the capital tax payment, as can be derived from Proposition 1.

Proposition 5 Increasing the capital tax rate $\tau_{\omega}$ either increases or reduces the critical investment threshold.

Proof. The algebraic sign of the partial derivative is ambiguous

$$
\frac{\partial \pi_{\tau}^{*}}{\partial \tau_{\omega}}=\underbrace{\frac{\left(\sqrt{\alpha_{\tau}^{2}+2 \sigma_{\tau}^{2} r_{\tau}}-\alpha_{\tau}\right)\left(\alpha_{\omega} r_{\tau}-\gamma \alpha_{\tau}\right)+\gamma r_{\tau} \sigma_{\tau}^{2}+2 r_{\tau}^{2}\left[\sigma_{\omega}\left(\sigma_{\omega} \tau_{\omega}-\rho \sigma_{\pi}\right)-\gamma \sqrt{\alpha_{\tau}^{2}+2 \sigma_{\tau}^{2} r_{\tau}}\right]}{2 r_{\tau}^{2} \sqrt{\alpha_{\tau}^{2}+2 \sigma_{\tau}^{2} r_{\tau}}}}_{\gtreqless 0} .
$$

In the limiting case without tax base uncertainty $\left(\sigma_{\omega}=0\right)$, and thus cash flow uncertainty only, the partial derivative simplifies to

$$
\left.\frac{\partial \pi_{\tau}^{*}}{\partial \tau_{\omega}}\right|_{\sigma_{\omega}=0}=\frac{\overbrace{\left(\sqrt{\alpha_{\tau}^{2}+2 r_{\tau} \sigma_{\pi}^{2}}-\alpha_{\tau}\right)}^{>0} \overbrace{\left(\alpha_{\omega} r_{\tau}-\alpha_{\tau} \gamma\right)}^{\gtrless_{0} 0}-\overbrace{\gamma r_{\tau}}^{\geq 0} \overbrace{\left(2 r_{\tau} \sqrt{\alpha_{\tau}^{2}+2 r_{\tau} \sigma_{\pi}^{2}}-\sigma_{\pi}^{2}\right)}^{\underbrace{2 r_{\tau}^{2} \sqrt{\alpha_{\tau}^{2}+2 r_{\tau} \sigma_{\pi}^{2}}}_{>0}}}{\underbrace{<}_{>0}},
$$

which can take either algebraic sign, as can be shown for $\alpha_{\pi}=\alpha_{\omega}=0$

$$
\left.\frac{\partial \pi_{\tau}^{*}}{\partial \tau_{\omega}}\right|_{\alpha_{\pi}=\alpha_{\omega}=\sigma_{\omega}=0}=\gamma\left(\frac{\sigma_{\pi}}{\sqrt{8 r_{\tau}^{3}}}-1\right)\left\{\begin{array}{c}
> \\
= \\
<
\end{array}\right\} 0 \Leftrightarrow \sigma_{\pi}^{2}\left\{\begin{array}{l}
> \\
= \\
<
\end{array}\right\} 8 r_{\tau}^{3} .
$$

\footnotetext{
${ }^{19}$ The non-monotonicity of the option value with respect to the interest rate follows from the assumption of an arithmetic Brownian motion. When a geometric Brownian motion is used, call option values increase with increasing interest rates. See Hull (2015), p. 237.
} 
Thus, for $\sigma_{\pi}^{2}<8 r_{\tau}^{3}$ paradoxical capital tax rate effects occur. By contrast, for extreme tax base uncertainty we obtain normal effects

$$
\lim _{\sigma_{\omega} \rightarrow \infty} \frac{\partial \pi_{\tau}^{*}}{\partial \tau_{\omega}}=+\infty
$$

regardless of the levels of $\alpha_{\pi}, \alpha_{\omega}$, and $\sigma_{\pi}$. Continuity with respect to $\sigma_{\omega} \geq 0$ implies that $\frac{\partial \pi_{\tau}^{*}}{\partial \tau_{\omega}}<0$ for small volatilities and $\frac{\partial \pi_{\tau}^{*}}{\partial \tau_{\omega}}>0$ for sufficiently high volatilities.

Corollary 3 Under sufficiently high pre-tax interest rates paradoxical capital tax rate effects prevail.

Proof. In the limiting case $r \rightarrow \infty$ the algebraic sign of the partial derivative is always non-positive:

$$
\lim _{r \rightarrow \infty} \frac{\partial \pi_{\tau}^{*}}{\partial \tau_{\omega}}=-\gamma \leq 0
$$

Here, the capital tax-exempted option value clearly favors the real investment over the default alternative. In contrast to paradoxical effects identified in prior literature under certainty (Wagner and Dirrigl 1980, Sureth and Maiterth 2008) this effect is caused by uncertainty and flexibility.

Numerical examples further clarify that either algebraic sign of $\partial \pi_{\tau}^{*} / \partial \tau_{\omega}$ is possible. In the following, we show which effect prevails under certain conditions. One of the major determinants of the capital tax effect is the growth parameter $\alpha_{\tau}$. For increasing net cash flows $\left(\alpha_{\tau}>0\right)$, increasing capital tax rates tend to reduce the critical investment threshold. If the expected level of after-tax cash flows decreases over time $\left(\alpha_{\tau}<0\right)$ increasing capital tax rates tend to delay investment. These opposing effects are shown for the parameter setting $r=0.04, \alpha_{\pi}=0.04$ (left hand side), $\alpha_{\pi}=-0.04$ (right hand side), $\alpha_{\omega}=0, \sigma_{\pi}=0.1, \sigma_{\omega}=1, \rho=0, \tau_{r}=0.25, \gamma=1$ in Figure $2 .^{20}$

\footnotetext{
${ }^{20}$ It should be noted that the values for $\sigma_{\pi}$ and $\sigma_{\omega}$ typically differ substantially, because $\sigma_{\pi}$ is the volatility of cash flows, which can be regarded as the return from an investment into assets, whereas $\sigma_{\omega}$ denotes the volatility of the capital tax base, i.e. the assessed invested assets.
} 

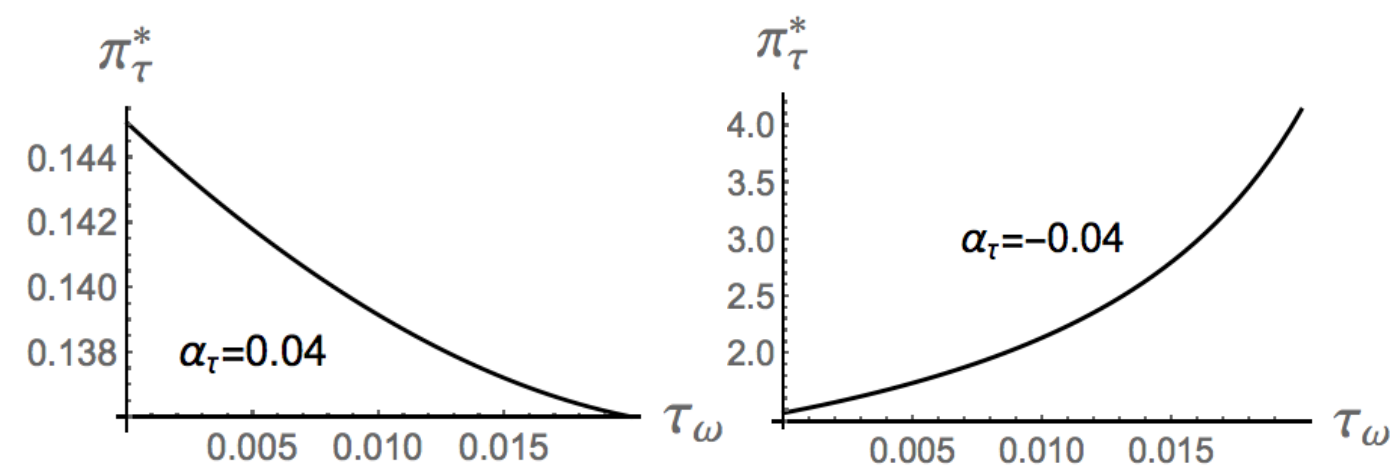

Figure 2: Critical investment threshold as a function of the capital tax rate $\tau_{\omega}$ for $r=0.04, \alpha_{\omega}=0, \sigma_{\pi}=0.1, \sigma_{\omega}=1, \rho=0, \tau_{r}=0.25$ and $\gamma=1$

If the default alternative is capital tax-exempt $(\gamma=0)$, which represents the case of a special asset tax, expression (25) simplifies to

$$
\left.\frac{\partial \pi_{\tau}^{*}}{\partial \tau_{\omega}}\right|_{\gamma=0}=\frac{\overbrace{\alpha_{\omega}}^{\gtrless 0} \overbrace{\left(\sqrt{\alpha_{\tau}^{2}+2 \sigma^{2} r_{\tau}}-\alpha_{\tau}\right)}^{>0}+2 r_{\tau} \overbrace{\sigma_{\omega}\left(\sigma_{\omega} \tau_{\omega}-\rho \sigma_{\pi}\right)}^{\sum_{0} 0}}{\underbrace{2 r_{\tau} \sqrt{\alpha_{\tau}^{2}+2 \sigma^{2} r_{\tau}}}_{>0}} .
$$

Even for this capital tax-exempt default alternative, increasing the capital tax rate can either accelerate or delay investment, although numerical examples indicate that normal effects are much more likely. The ambiguity of the effect depends on the correlation of the stochastic processes as can be seen from the numerical example $r=0.04, \alpha_{\pi}=\alpha_{\omega}=0$, $\sigma_{\pi}=0.1, \sigma_{\omega}=1, \rho=1$ (left hand side), $\rho=0$ (right hand side), $\tau_{r}=0.25, \gamma=0$ in Figure 3. In this special case, however, variations of the capital tax rate $\tau_{\omega}$ are almost negligible, as can be observed from the small-scale differences of the ordinate values, especially for $\rho=0$. In the latter case, the partial derivative reduces to

$$
\left.\frac{\partial \pi_{\tau}^{*}}{\partial \tau_{\omega}}\right|_{\alpha_{\omega}=\gamma=\rho=0}=\frac{\sigma_{\omega}^{2} \tau_{\omega}}{\sqrt{\alpha_{\pi}^{2}+2 \sigma^{2} r_{\tau}}}>0,
$$

so that paradoxical tax effects cannot be observed any more. 

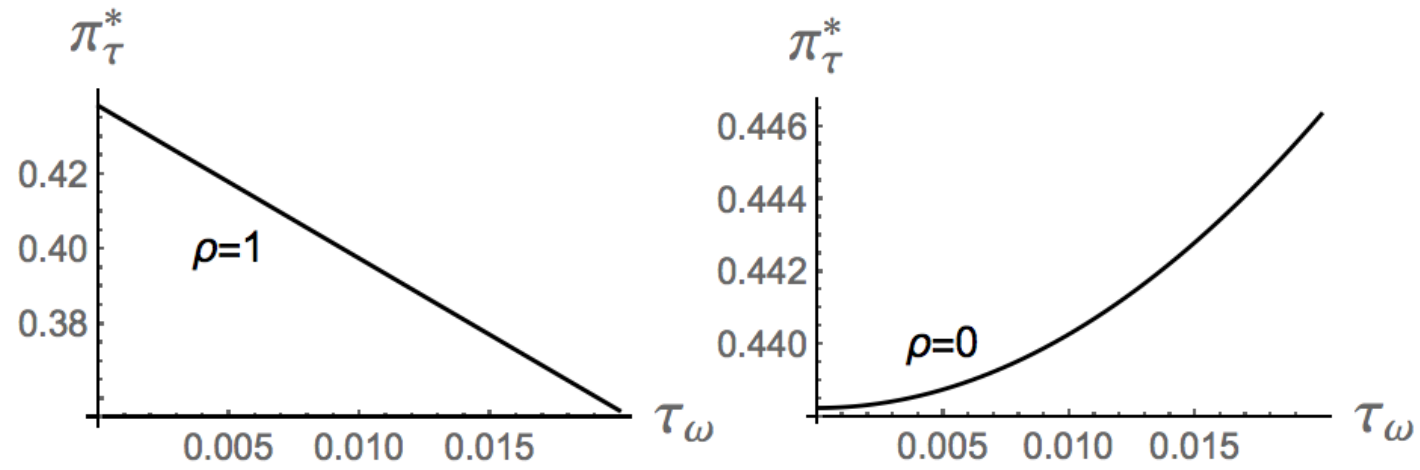

Figure 3: Critical investment threshold as a function of the capital tax rate $\tau_{\omega}$ for $r=0.04, \alpha_{\pi}=\alpha_{\omega}=0, \sigma_{\pi}=0.1, \sigma_{\omega}=1, \tau_{r}=0.25$ and $\gamma=0$

We can estimate the overall relevance of capital tax uncertainty by comparing the critical investment threshold with $\left(\sigma_{\omega}>0\right)$ and without capital tax uncertainty $\left(\sigma_{\omega}=0\right)$ for different values of the capital tax rate. As an example with the parameters $r=0.04$, $\alpha_{\pi}=\alpha_{\omega}=0, \sigma_{\pi}=0.1, \rho=0, \tau_{r}=0.25$ and $\gamma=1$, the solid line in Figure 4 shows $\pi_{\tau}^{*}$ for the case with high capital tax uncertainty $\left(\sigma_{\omega}=2.5\right)$, the dashed line for deterministic capital taxes $\left(\sigma_{\omega}=0\right)$. We find that for small capital tax rates, capital tax uncertainty does not affect investment timing significantly, because total uncertainty is dominated by cash flow uncertainty. For higher capital tax rates, however, neglecting capital tax uncertainty would induce major mistakes in investment timing, as the difference of critical investment thresholds may reach as much as $10 \%$ of the initial value.

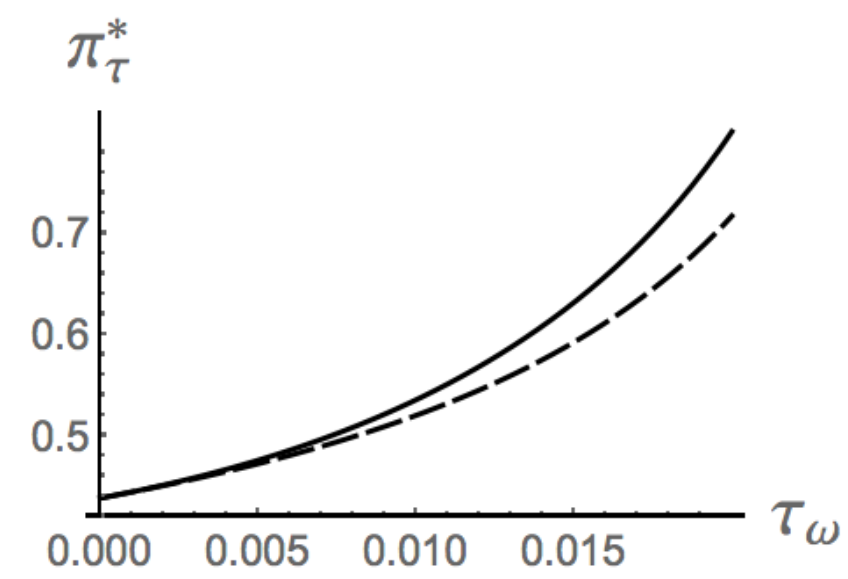

Figure 4: Critical investment thresholds as a function of the capital tax rate $\tau_{\omega}$ for $r=0.04, \alpha_{\pi}=\alpha_{\omega}=0, \sigma_{\pi}=0.1, \sigma_{\omega} \in\{0,2.5\}, \rho=0, \tau_{r}=0.25$ and $\gamma=1$ 
Figure 5 shows the critical investment threshold if capital taxes are the only random variable $\left(\sigma_{\pi}=0, \sigma_{\omega} \in\{1,2,3,4\}\right)$, all else as in Figure 4 . The thick solid line represents the case $\sigma_{\omega}=1$, the thick dashed line $\sigma_{\omega}=2$, the thin solid line $\sigma_{\omega}=3$, and the thin dotted line $\sigma_{\omega}=4$. In this setting, the capital tax rate considerably affects the investment timing decision. The impact of the capital tax rate can differ dramatically for different levels of capital tax uncertainty and is stronger for higher capital tax uncertainty in this example. As a consequence, investors and tax legislators should account for capital tax uncertainty especially if cash flow uncertainty is low. It is obvious that careful estimations of the degree of capital tax uncertainty are necessary for correctly anticipating the impact of capital tax rate adjustments.

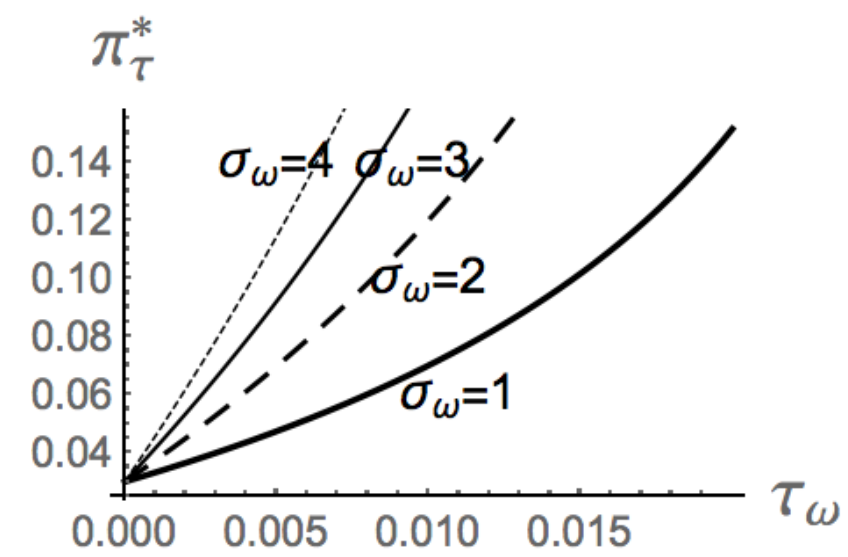

Figure 5: Critical investment thresholds as a function of the capital tax rate $\tau_{\omega}$ for $r=0.04, \alpha_{\pi}=\alpha_{\omega}=0, \sigma_{\pi}=0, \sigma_{\omega} \in\{1,2,3,4\}, \rho=0, \tau_{r}=0.25$ and $\gamma=1$

Summing up the tax rate analysis, apparently paradoxical capital tax rate effects $\left(\partial \pi_{\tau}^{*} / \partial \tau_{\omega}<\right.$ 0) are more likely for

- high pre-tax interest rates $(r \rightarrow \infty)$,

- high volatilities $\left(\sigma_{\omega} \rightarrow \infty\right)$,

- high positive correlations $(\rho \rightarrow 1)$,

- increasing cash flows $\left(\alpha_{\tau}>0\right)$, 
- high taxation of the default alternative $(\gamma \rightarrow 1)$.

Our results show that identical tax policy actions may yield very different economic results, which particularly depend on the expected cash flow structure and volatility of the project or industry under consideration. Whatever the tax legislator's objectives may be, it is unlikely that they can be reached by capital taxes, given the ambiguity of investment effects. The tax legislator should therefore state explicitly which type of investment effect is considered desirable. If, for example, investment by high-tech firms with (typically) increasing cash flows and high risks $\left(\alpha_{\pi}>0, \sigma_{\pi} \gg 0\right)$ should be encouraged, reducing the capital tax rate would likely be dysfunctional.

\section{Conclusions and implications}

We analyze the impact of capital tax uncertainty on timing decisions of risky investments. Capital tax uncertainty is typically caused either by tax policy uncertainty or uncertainty in the outcome of tax audits. The valuation of assets in tax audits often leads to adjustments of the capital tax base. This uncertainty in tax assessment has to be anticipated when making an investment decision. An uncertain tax environment is currently created by the mere possibility of future new or increased capital taxes such as wealth or property taxes. Thus, irrespective of the actual future design of a capital tax, it is the threat of new capital taxes, or an increase in existing capital taxes that may already cause uncertainty.

If assets generate stochastic cash flows, the fair value of these assets as measured by present values is also stochastic. Thus, cash flow uncertainty induces capital tax base uncertainty whenever the tax base is correlated with the stochastic cash flows. Additional capital tax uncertainty arises from unclear definitions of taxable tangible and intangible assets or when the tax law permits valuation discretion.

By modelling the volatility of the capital tax base as a proxy for all types of capital tax uncertainty we are the first to identify the distortive power of stochastic capital taxes 
on risky investments. We find that capital tax volatility ambiguously affects investment timing. As normally expected, increased overall volatility decelerates risky investments due to the increased option value. Increased capital tax volatility, however, may either accelerate or delay investment. Unexpectedly, as long as capital tax uncertainty does not exceed a certain critical level, increases in tax volatility accelerate investment implying an increase in the investor's propensity to carry out risky projects. Furthermore, for high correlations and high cash flow uncertainty, even low levels of capital tax uncertainty can generate paradoxical investor reactions. This finding is interesting for political debates because it sheds light on the importance of unexpected investor reactions when designing or reforming capital taxes.

The relevance of this effect is supported by our sensitivity analysis of the interaction of volatility and the correlation of the capital tax base and operating cash flows. Increasing the correlation of cash flows and asset values reduces the critical investment threshold and hence accelerates investment. Ceteris paribus, this result somewhat surprisingly implies that fair value accounting for capital tax purposes, which is supposedly correlated with cash flows may be less harmful for real investment than historical cost valuation, which is at best weakly related to cash flows.

Our model and our numerical analysis provide insights for the design of capital taxes in general. We show that specific capital taxes like pure property taxes generally induce different investment timing effects than a general wealth tax that also taxes financial assets. Our model reveals that broadening the capital tax base from a special asset tax to a general wealth tax unexpectedly delays risky investment if total volatility is high and interest rates are low. This result helps us to understand that general wealth taxes are much more vulnerable to generate paradoxical investor behavior and thereby counteract tax policy intentions. In this respect, our findings explain the empirical finding that many countries levy property taxes while only a limited number of countries levies wealth taxes. 
Furthermore, changes in the capital tax rate can induce either normal or paradoxical investment timing effects. For high-growth investments the critical investment threshold decreases after an increase of the capital tax rate, which can be interpreted as a paradoxical acceleration. Further conditions that favor paradoxical capital tax rate effects are high pre-tax interest rates, high volatilities, and high positive correlations. In contrast, for sufficiently low cash flow growth rates, normal reactions are more likely to prevail.

Our results indicate that the tax legislator should be aware of the distortive power of capital tax uncertainty. The large number of parameters that facilitate paradoxical investment responses indicates that such paradoxical tax effects are likely to occur. Therefore, it is doubtful whether the tax legislator's efficiency and redistributive objectives can be reached by capital taxes.

Our analysis is subject to several limitations. We use a purely partial analytical model, which does not allow politicians to draw conclusions about the overall revenue and distributional effects. Rather, our analysis of investment effects should precede an estimation of capital tax revenues. Furthermore, our decision-maker perspective is still characterized by several restrictive assumptions. For example, we abstract from effects of various financing channels but focus on equity financing only. Consequently, financial constraints, tax shields from interest deductions, and liquidity considerations are disregarded in the model. However, debt financing can be implicitly included in our model, assuming that debt-related payments are already included in the cash flows.

Moreover, we abstract from cross-border issues, which are often assumed to offer substantial tax avoidance potential. We neglect compliance costs that are likely to increase in tax uncertainty. Like most previous studies from the real options literature we restrict our study to risk neutral investors. We therefore conjecture that our results on the effects of capital tax uncertainty represent a lower bound for such effects on risk averse decision-makers. 
It should be noted, that it is not self-evident to what extent the tax legislator can actually influence tax uncertainty. Whereas high-frequency tax reforms and tax audit uncertainty are certainly the result of fiscal activities, many tax reform discussions are triggered by lobbyists rather than by deliberate governmental action.

For future research on tax effects under both cash flow and tax uncertainty, our model can be extended with respect to debt financing, compliance costs, different attitudes towards risk or more complex tax rules. Moreover, our model is well suited to capture the effects of value added tax (VAT) uncertainty. Since many tax authorities are reluctant to refund input VAT, net VAT payment is a stochastic process that is subject to tax authorities' discretion. If investments are high, denial of input VAT refund can threaten a firm's existence. As a consequence, VAT uncertainty is likely to affect investment behavior.

As our findings are purely theoretical we think it is even more interesting to derive testable hypotheses for empirical or quasi-experimental investigations. Although timing effects of real investment are notoriously hard to observe, investment spikes might serve as a proxy for investment timing reactions to a tax reform and can be used in event studies. Recent capital tax reforms or reform discussions such as the intensive pre-election discussions on reintroducing a wealth tax in 2003-2005 and 2012-2013 in Germany, the introduction of a new valuation approach for the German real estate tax in 2009, the 2012 and 2013 wealth tax reforms in France, and the 2006 and subsequent wealth tax reforms in Norway can serve as events for a quasi-experimental setting and open our research question to an empirical investigation. 


\section{References}

Agliardi, E. (2001). Taxation and Investment Decisions: A Real Options Approach. Australian Economic Papers, 40(1), pp. 44-55.

Allee, K. D., Lynch, D. P., Petroni, K. R., and Schroeder, J. H. (2015). Do Property Taxes Affect Real Operating Decisions and Market Prices for Crude Oil? Contemporary Accounting Research, 32(2), pp. 736-762.

Alm, J. (1988). Uncertain tax policies. Individual behavior and welfare. American Economic Review, 78(1), pp. 237-245.

Alvarez, L. H. R. and Koskela, E. (2008). Progressive Taxation, Tax Exemption, and Irreversible Investment under Uncertainty, Journal of Public Economic Theory, 10(1), pp. 149-169.

Auerbach, A. J. and Hassett, K. A. (2015). Capital Taxation in the Twenty-First Century. American Economic Review, 105(5), pp. 38-42.

Balogh, T. (1964). A Note on the Wealth Tax. The Economic Journal, 74(293), pp. $221-224$.

Beck, P. J. and Jung, W. (1989). Taxpayer Compliance under Uncertainty. Journal of Accounting and Public Policy, 8(1), pp. 1-27.

Beck, P. J. and Lisowsky, P. (2014). Tax Uncertainty and Voluntary Real-Time Tax Audits. The Accounting Review, 89(3), pp. 867-901.

Bentick, B. L. (1979). The Impact of Taxation and Valuation Practices on Timing and Efficiency of Land Use. Journal of Political Economy, 87(4), pp. 859-868.

Bird, R. M. (1991). The Taxation of Personal Wealth in International Perspective. Canadian Public Policy, 17(3), pp. 322-334.

Bizer, D. S. and Judd, K. L. (1989). Taxation and uncertainty. American Economic Review, Papers and Proceedings, 79(2), pp. 331-336.

BMF (2016). Die wichtigsten Steuern im internationalen Vergleich 2015. Berlin: Bundesministerium der Finanzen (Ministery of Finance).

Brennan, G. and Nellor, D. (1982). Wealth, Consumption and Tax Neutrality. National Tax Journal, 35(4), pp. 427-436. 
Burbidge, J. (1991). The Allocative and Efficiency Effects of Wealth Taxes. Canadian Public Policy, 17(3), pp. 264-278.

Craft, E. D. and Schmidt, R. M. (2005). An Analysis of the Effects of Vehicle Property Taxes on Vehicle Demand. National Tax Journal, 58(4), pp. 697-720.

Davies, J. B. (1991). The Distributive Effects of Wealth Taxes. Canadian Public Policy, 17(3), pp. 279-308.

De Simone, L., Sansing, R. C., and Seidman, J. K. (2013). When are Enhanced Relationship Tax Compliance Programs Mutually Beneficial? The Accounting Review, 88(6), pp. 1971-1991.

De Simone, L. and Stomberg, B. (2013). Do investors differentially value tax avoidance by income mobile firms?, Working Paper, available at SSRN, http://ssrn.com/abstra ct $=2102903$.

Deloitte (2004-2015). Tax Guides. London: DTTL.

Diller, M., Kortebusch, P., Schneider, G., and Sureth, C. (2016). Boon or Bane? Advance Tax Rulings as a Measure to Mitigate Tax Uncertainty and Foster Investment. European Accounting Review, published online, doi: 10.1080/09638180.2016.1169939.

Dixit, A. K. and Pindyck, R. S. (1994). Investment under Uncertainty. (Princeton: Princeton University Press).

Domar, E. D. and Musgrave, R. A. (1944). Proportional Income Taxation and RiskTaking. Quarterly Journal of Economics, 58(3), pp. 388-422.

Dye, R. F., McGuire, T. G., and Merriman, D. F. (2001). The Impact of Property Taxes and Property Tax Classification on Business Activity in the Chicago Metropolitan Area. Journal of Regional Science, 41(4), pp. 757-777.

Edmiston, K. D. (2004). Tax Uncertainty and Investment: A Cross-Country Empirical Examination. Economic Inquiry, 42(3), pp. 425-440.

EY (2014). Bridging the divide. Highlights form the 2014 Tax risk and controvery survey. EYMG Limited.

EY (2015). Tax Guides Archive. EY Global Limited, www.ey.com/GL/en/Services/Tax/ Global-tax-guide-archive. 
Givati, Y. (2009). Resolving Legal Uncertainty: The Unfulfilled Promise of Advance Tax Rulings. Virginia Tax Review, 29(1), pp. 137-175.

Gries, T., Prior, U., and Sureth, C. (2012). A Tax Paradox for Investment Decisions under Uncertainty. Journal of Public Economic Theory, 14(3), pp. 521-545.

Guenther, D., Matsunaga, S., and Williams, B. (2016). Is Tax Avoidance Related to Firm Risk? The Accounting Review, in press, doi: 10.2308/accr-51408.

Hansson, A. (2008). The Wealth Tax and Entrepreneurial Activity. Journal of Entrepreneurship, 17(2), pp. 139-156.

Hassett, K. A. and Metcalf, G.E. (1999). Investment with uncertain tax policy: does random tax policy discourage investment? Economic Journal, 109(457), pp. 372393.

Hoppe, T., Maiterth, R., and Sureth, C. (2016). Eigenkapitalverzehr und Substanzbesteuerung deutscher Unternehmen durch eine Vermögensteuer - eine empirische Analyse, Zeitschrift für betriebswirtschaftliche Forschung, 68(1), pp. 3-45.

Hull, J. C. (2015). Options, Futures and other Derivatives. 9th edition. London: Pearson.

IBFD (2016). Tax Research Database. Amsterdam: IBFD.

IMF (2013). World Economic and Financial Surveys: Fiscal Monitor - Taxing Times. Washington, DC: International Monetary Fund.

IMF (2014). Fiscal Policy and Income Inequality. IMF Policy Paper. Washington, DC: International Monetary Fund.

Jacob, M. and Schütt, H. (2013). Firm Valuation and the Uncertainty of Future Tax Avoidance. arqus Quantitative Research in Taxation, Working Paper No. 149, and FAccT Center Working Paper No. 13/2013, available at SSRN, http://ssrn.com /abstract $=2347330$.

Jacob, M., Wentland, K., and Wentland, S. (2016). Firm Tax Uncertainty, Cash Holdings, and the Timing of Large Investment. Working Paper, available at SSRN: http://ssrn.com/abstract $=2518243$.

Kocherlakota, N. R. (2005). Zero Expected Wealth Taxes: A Mirrlees Approach to Dynamic Optimal Taxation. Econometrica, 73(5), pp. 1587-1621. 
KPMG (2004-2015): Global Corporate Tax Handbook. Amsterdam: IBFD

Lisowsky, P., Robinson, L. A., and Schmidt, A. (2013). Do Publicly Disclosed Tax Reserves Tell Us About Privately Disclosed Tax Shelter Activity? Journal of Accounting Research, 51(3), pp. 583-629.

Logue, K. D. (2005). The Problem of Tax Law Uncertainty and the Role of Tax Insurance. Virginia Tax Review, 25(2), pp. 339-414.

McGuire, S. T., Neuman, S. S., and Omer, T. C. (2013). Sustainable Tax Strategies and Earnings Persistence. Working Paper, available at SSRN, http://ssrn.com/abstract= 1950378.

Michalos, A. C. (1988). A Case for a Progressive Annual Net Wealth Tax. Public Affairs Quarterly, 2(2), pp. 105-140.

Mieszkowski, P. (1972). The Property Tax: an Excise Tax or a Profits Tax? Journal of Public Economics, 1(1), pp. 73-96.

Mills, D. E. (1981). The Non-Neutrality of Land Value Taxation. National Tax Journal, $34(2)$, pp. 125-129.

Mills, L., Robinson, L. A., and Sansing, R. (2010). FIN 48 and Tax Compliance. The Accounting Review, 85(5), pp. 1721-1742.

Mintz, J. M. (1991). The Role of Wealth Taxation in the Overall Tax System. Canadian Public Policy, 17(3), pp. 248-263.

Müller, J. (2014). The Challenge of Assessing Market Value of Private Companies Using a Standardized Combination Method for Tax Purposes - Lessons to be Learnt from Past Experience. European Accounting Review, 23(1), pp. 117-141.

Neuman, S. S., Omer, T. C., and Schmidt, A. P. (2016). Assessing Tax Risk: Practitioners Perspectives. Working Paper, available at SSRN, http://ssrn.com/abstract= 2579354 .

Niemann, R. (1999). Neutral Taxation under Uncertainty. FinanzArchiv, 56(1), pp. $51-66$.

Niemann, R. (2004). Tax Rate Uncertainty, Investment Decisions, and Tax Neutrality. International Tax and Public Finance, 11(3), pp. 265-281. 
Niemann, R. (2011). The impact of tax uncertainty on irreversible investment. Review of Managerial Science, 5(1), pp. 1-17.

Niemann, R. and Sureth, C. (2004). Tax Neutrality under Irreversibility and Risk Aversion. Economics Letters, 84(1), pp. 43-47.

Niemann, R. and Sureth, C. (2005). Capital Budgeting with Taxes under Uncertainty and Irreversibility. Journal of Economics and Statistics, 225(1), pp. 77-95.

Niemann, R. and Sureth, C. (2013). Sooner or Later? - Paradoxical investment effects of capital gains taxation under simultaneous investment and abandonment flexibility. European Accounting Review, 22(2), pp. 367-390.

Niemann, R. and Sureth-Sloane, C. (2015). Investment Timing Effects of Wealth Taxes under Unvertainty and Irreversibility. arqus Quantitative Research in Taxation, Working Paper No. 192, and CESifo Working Paper No. 5610, available at SSRN: http://ssrn.com/abstract $=2706440$.

OECD (2015a). Adressing the Tax Challenges of the Digital Economy, Action 1 - 2015, Final Report, OECD/G20 Base Erosion Profit Shifting Project. Paris: OECD Publishing.

OECD (2015b). Revenue Statistics 2015. Paris: OECD Publishing.

Panteghini, P. M. (2004). Wide versus Narrow Tax Bases under Optimal Investment Timing. FinanzArchiv, 60(4), pp. 482-493.

Panteghini, P. M. (2005). Asymmetric taxation under incremental and sequential investment. Journal of Public Economic Theory, 7(5), pp. 761-779.

Piketty, T. (2014). Capital in the Twenty-First Century. Cambridge, MA, London: Harvard University Press.

PwC (2004-2015): Worldwide Tax Summaries. www.pwc.com/taxsummaries: PwC

Skinner, J. (1988). The Welfare Cost of Uncertain Tax Policy. Journal of Public Economics, 37(2), pp. 129-145.

Stiglitz, J. E. (1969). The Effects of Income, Wealth, and Capital Gains Taxation on Risk-Taking. The Quarterly Journal of Economics, 83(2), pp. 263-283.

Sureth, C. (2002). Partially irreversible investment decisions and taxation under uncertainty - a real option approach. German Economic Review, 3(2), pp. 185-221. 
Sureth, C. and Maiterth, R. (2008). The Impact of Minimum Taxation by an Imputable Wealth Tax on Capital Budgeting and Business Strategy of German Companies. Review of Managerial Science, 2(2), pp. 81-110.

Thurow, L. C. (1972). Net Worth Taxes. National Tax Journal, 25(3), pp. 417-423.

Wagner, F. W. and Dirrigl, H. (1980). Die Steuerplanung der Unternehmung. Stuttgart et al.: Fischer.

Wijnbergen, S. v. and Estache, A. (1999). Evaluating the Minimum Asset Tax on Corporations: an Option Pricing Approach. Journal of Public Economics, 71(1), pp. $75-96$. 